\title{
Scaphoidectomy and 4-corner arthrodesis with headless compression screws: results, complications and their treatment
}

\author{
Kira Vande Voorde, Pieter Caekebeke, Joris Duerinckx
}

From the Department of Orthopaedic Surgery, ZOL Genk

Scaphoidectomy and 4-corner arthrodesis is a common salvage surgery for degenerative wrist pathology. The purpose of this study was to evaluate the results of this procedure performed with headless compression screws, with a special focus on postoperative complications and their treatment. We assessed 36 wrists in 31 patients that were treated between 2009 and 2017. Mean follow-up was 5.2 years (range 2.9- 9.4). Pain was expressed on a Visual Analog Scale. The Quick Disabilities of the Arm, Shoulder and hand (qDASH) questionnaire and Michigan Hand Outcome Questionnaire (MHOQ) were used to assess patient functionality and satisfaction. Range of motion and grip strength of both wrists were measured. Radiographs of the operated wrist were evaluated. Mean pain score was $1.5 \pm 2.3$ with $19 \%$ of patients being completely free of pain also during activity. Mean qDASH was $44 \pm 20$ and mean MHOQ was 10 \pm 5 . Mean flexion-extension arc of the operated wrist was $69^{\circ}$ and $61 \%$ of the contralateral wrist. Mean grip strength was $35 \mathrm{~kg}$ and $89 \%$ of the opposite wrist. Non-union was observed in two patients. Two patients required hardware removal and in three patients a pisiformectomy was performed. Conversion to total wrist arthrodesis was needed in one patient. We observed postoperative complications in $\mathbf{2 8 \%}$ of our patients. Most complications can successfully be treated with additional surgery. The presence of

Conflict of Interest. Each author certifies that he or she has no commercial associations (eg, consultancies, stock ownership, equity interest, patent/licensing arrangements, etc) that might pose a conflict of interest in connection with the submitted article.

Ethical Review committee. An institutional review board approval for this study and a written informed consent of each included patient was obtained (Eudract B371201942661). pisotriquetral arthritis should be assessed before surgery and treated with pisiform excision.

Keywords : Scaphoidectomy ; arthrodesis ; fusion ; screw ; outcome ; complications.

\section{INTRODUCTION}

Excision of the scaphoid combined with "4-corner" arthrodesis of the capitate, lunate, triquetrum and hamate was first described by Watson et al. in 1984 (1). Indications for this procedure include painful scapholunate advanced collapse (SLAC), scaphoid nonunion advanced collapse (SNAC), midcarpal arthritis and avascular necrosis of the scaphoid or the capitate. Good to excellent long-term results can be expected $(2,3)$. Different fixation methods have been described to stabilize the midcarpal joint like staples, K-wires, and plate and screws (3). Two decades ago, Krakauer et al. (4) and Tomaino et

Kira Vande Voorde, MD

Pieter Caekebeke, MD

- Joris Duerinckx, MD

Department of Orthopaedic Surgery, ZOL Genk

Correspondence : Joris Duerinckx, Department of Orthopaedic Surgery, ZOL Genk, Schiepse Bos 6, 3600 Genk, Belgium, Phone: +32 89326118 .

Email : joris.duerinckx@zol.be

- 2021, Acta Orthopædica Belgica. 
al. (5) introduced the use of headless compression screws (HCS) for this indication (6). This technique seems to be most favorable, because this hardware is not prominent and the bony compression that is provided by the screws is beneficial for bone healing (7). Nevertheless, postoperative complications have been reported (6,8-11).

The goal of this study was to evaluate the outcome and complications after scaphoidectomy and 4-corner arthrodesis with headless compression screws with a follow-up of at least 2 years, and how these complications can be managed or prevented.

\section{MATERIALS AND METHODS}

An Institutional Review Board (IRB) approval for this study and a written informed consent of each included patient was obtained (Eudract B371201942661).

We performed 54 scaphoidectomy and 4-corner arthrodesis procedures in our institution from November 2009 until October 2017. All surgeries were performed by a single surgeon (JD) with a level 3 expertise for this surgery according to Tang and Giddins (12). For this retrospective follow-up study, we were able to recruit 36 operated wrists in 31 patients. Five patients underwent the procedure bilaterally. Three patients died and 15 could not be reached or were not able to participate. The chart file of each included patient was reviewed to collect data on patient demographics, surgical indication, operative procedure and postoperative complications. Patients were invited for a follow-up consultation, at which time we measured flexionextension and radial-ulnar deviation of both wrists using a goniometer. Grip strength was measured bilaterally with a Jamar dynamometer in the second position. Postoperative pain, at rest and during activity, was expressed on a 10-point Visual Analog Scale (VAS ; $0=$ no pain ; $10=$ worst pain). The Dutch version of the Quick Disabilities of the Arm, Shoulder, and Hand Questionnaire (qDASH) was used to evaluate overall functionality of the operated extremity. Patient satisfaction was evaluated by the Dutch version of the Michigan Hand Outcome Questionnaire (MHOQ) part 6 for both hands. Anteroposterior and lateral radiographs of the wrist were judged for union, hardware complications, radiolunate arthritis and possible other findings. Of all measurements, mean and standard deviation were calculated. For the MHOQ part 6, a sign test and signed-rank test were performed to determine if the difference between the operated and nonoperated hand was statistically significant. These tests do not require normality of the patient specific differences between the operated and non-operated wrist.

There were 24 males and 7 females. 5 patients underwent the procedure bilaterally, but not simultaneously. Mean age was 62 years (range 44-82). 11 patients smoked (30.6\%). 24 of the 36 procedures concerned the dominant wrist (67\%). Mean followup time was 5.2 years (range 2.9-9.3). Surgical indications included SNAC wrist grade II $(n=2)$, SNAC wrist grade III $(n=9)$, SLAC wrist grade II $(n=8)$, SLAC wrist grade III $(n=9)$, midcarpal arthritis $(n=7)$, Preiser's disease $(n=1)$.

The surgical technique was based on Ozyurekoglu et al. (8) with the only adaptation that we routinely performed a neurectomy of the posterior interosseus nerve. Bone fixation was performed with Mini Acutrak 2 screws (Acumed LLC, Hillsboro, OR, USA). In 9 cases, a bicolumnar fixation method with one triquetrum-hamate screw according to Ozyurekoglu was used. In the other 27 cases, there was a diagonal screw fixation of the triquetrum, hamate and capitate as described by Draeger et al. (9) In 7 cases, capitolunate fixation was performed with two screws instead of one because bone quality was evaluated as suboptimal. In all cases, the dorsal intercalated segment instability (DISI) was corrected. A total of 15 concomitant procedures were performed in 14 patients : radial styloidectomy $(n=2)$, carpal tunnel release $(n=8)$, in situ release of the ulnar nerve at the elbow $(n=2)$, ulnar shortening osteotomy $(\mathrm{n}=1)$, Burton-Pellegrini procedure $(\mathrm{n}=1)$ and pisiformectomy $(\mathrm{n}=1)$. Postoperatively, the wrist was immobilized in a short-arm cast for 4 weeks, followed by automobilization and a removable splint for another 4 weeks. Strengthening exercises and progressive mobilization under supervision of a certified physiotherapist started 8 weeks after surgery. 


\section{RESULTS}

Postoperative range of motion of the wrist and grip strength are shown in Table I. Flexion averaged $34^{\circ}$ (range $15-56^{\circ}$ ) and extension $34^{\circ}$ (range 10 $60^{\circ}$ ). The mean flexion-extension arc was $61 \%$ of the contralateral wrist. Mean radial deviation was $15^{\circ}$ (range $4-25^{\circ}$ ) and mean ulnar deviation was $24^{\circ}$ (range $5-44^{\circ}$ ). The mean arc of radial-ulnar wrist motion was $54 \%$ of the contralateral side. Average grip strength of the operated hand was $35 \mathrm{~kg}$ (range $12-80 \mathrm{~kg}$ ), which corresponded to $89 \%$ of the grip strength of the contralateral side. For comparison with the contralateral side, only patients with unilateral surgery were included.

Residual wrist pain and the result of the functionality and satisfaction questionnaires are shown in Table I. 18 patients were pain free at rest $(50 \%)$ and 7 of them did not experience pain during activity (19\%). 30 patients completed the MHOQ for their control and operated wrist. The difference between both was calculated. Statistical analysis showed a significant negative difference in 16 patients $(53 \%)$, meaning that patient satisfaction of the operated wrist was lower than the non-operated wrist. In 9 patients (30\%), satisfaction of both wrists was the same. A minority of the patients $(17 \%)$ was more satisfied of their operated wrist than their control wrist.

Successful bone healing was achieved in 34 patients $(94 \%)$. Small calcifications in the scaphoid resection space were present in 25 cases $(69 \%)$. Degenerative changes at the radiolunate joint were observed in one patient (3\%) and at level of the distal radial ulnar joint in 7 cases (19\%).

We observed postoperative complications in 10 (28\%) of our patients (Table II). 7 patients $(19 \%)$ were reoperated and all complications, except for 2 , were considered solved at final follow-up.

\section{DISCUSSION}

Scaphoidectomy with 4-corner arthrodesis is a motion-sparing, limited wrist arthrodesis that has been studied extensively. Pain relief is typically excellent. $40-60 \%$ of normal wrist motion is maintained and $75-80 \%$ of normal grip strength can be expected (2). The results in our study confirm this. With an average grip strength of $89 \%$ of the contralateral site, our results score even higher than the values mentioned in literature.

Midcarpal wrist fusion decreases function of the operated upper extremity as demonstrated by high qDASH scores. It is unclear why the qDASH scores in our series score higher than the DASH scores in comparable series $(8,9)$. The qDASH score is not specific enough to examine this. Results can be obscured by concomitant elbow of shoulder pathology. The MHOQ score more specifically evaluates patient satisfaction of hand and wrist function. Since previous reports all use different questionnaires it is difficult to compare the results.

Table I. - Postoperative outcome after scaphoidectomy and 4-corner arthrodesis with headless compression screws.

Comparison of the current study with results in the literature

\begin{tabular}{|c|c|c|c|c|c|c|c|}
\hline & $\mathbf{N}$ & $\begin{array}{c}\text { Mean } \\
\text { follow-up } \\
\text { (years) }\end{array}$ & $\begin{array}{l}\text { Mean flexion- } \\
\text { extension arc }\left({ }^{\circ}\right)\end{array}$ & $\begin{array}{l}\text { Mean radio- } \\
\text { ulnar deviation } \\
\operatorname{arc}\left({ }^{\circ}\right)\end{array}$ & $\begin{array}{l}\text { Grip } \\
\text { strength } \\
\text { (kg) }\end{array}$ & VAS pain & $\begin{array}{l}\text { Mean } \\
\text { DASH } \\
\text { score }\end{array}$ \\
\hline Current study & 36 & 5.2 & 68 & 39 & 35 & $\begin{array}{c}\text { Rest: } 1.5 \pm 2.3 \\
\text { Activity: } 3.4 \pm 2.9\end{array}$ & qDASH 44 \\
\hline $\begin{array}{l}\text { Draeger et al. } \\
\text { (2014) }\end{array}$ & 11 & 3.3 & 88 & / & 32 & $1.8 \pm 2.4$ & DASH 17 \\
\hline $\begin{array}{l}\text { Ozyurekoglu } \\
\text { et al. (2012) }\end{array}$ & 33 & 0.7 & 71 & 35 & 29 & $0.6 \pm 1$ & DASH 13 \\
\hline $\begin{array}{l}\text { Richards et al. } \\
\text { (2011) }\end{array}$ & 19 & I & $\begin{array}{l}10-20 \text { in } 3 \text { patients } \\
30-60 \text { in } 16 \text { patients }\end{array}$ & / & l & / & / \\
\hline
\end{tabular}


Table II. - Postoperative complications after scaphoidectomy and 4-corner arthrodesis with headless compression screws

\begin{tabular}{|l|c|c|c|c|c|l|}
\hline & $\mathbf{N}$ & $\begin{array}{c}\text { Mean } \\
\text { follow-up } \\
\text { (years) }\end{array}$ & $\begin{array}{c}\text { Nonunion } \\
\text { (N) }\end{array}$ & $\begin{array}{c}\text { Hardware } \\
\text { problems } \\
\text { (N) }\end{array}$ & $\begin{array}{c}\text { Conversion to } \\
\text { total wrist fusion } \\
\text { (N) }\end{array}$ & \begin{tabular}{l} 
Other complications (N) \\
\hline Current study
\end{tabular} \\
\hline & 56 & $2(6 \%)$ & $3(8 \%)$ & $1(3 \%)$ & $\begin{array}{l}1 \text { pisiform instability } \\
1 \text { dysesthesia dorsal ulnar nerve } \\
1 \text { scar hypersensitivity } \\
1 \text { ulnar impaction syndrome }\end{array}$ \\
\hline $\begin{array}{l}\text { Richards et al. } \\
\text { (2011) }\end{array}$ & 19 & $/$ & $1(5 \%)$ & $3(16 \%)$ & $0(0 \%)$ & $\begin{array}{l}1 \text { ulnar styloid impaction syndrome } \\
1 \text { wrist stiffness }\end{array}$ \\
\hline $\begin{array}{l}\text { Ozyurekoglu et } \\
\text { al. (2012) }\end{array}$ & 33 & 0.7 & $2(6 \%)$ & $2(6 \%)$ & $1(3 \%)$ & $/$ \\
\hline $\begin{array}{l}\text { Draeger et al. } \\
\text { (2014) }\end{array}$ & 11 & 3.3 & $0(0 \%)$ & $1(9 \%)$ & $0(0 \%)$ & $/$ \\
\hline $\begin{array}{l}\text { Iordache et al. } \\
\text { (2016) }\end{array}$ & 27 & 1.0 & $3(11 \%)$ & $4(15 \%)$ & $1(4 \%)$ & $\begin{array}{l}1 \text { dysesthesia dorsal ulnar nerve } \\
1 \text { dysesthesia superficial radial nerve }\end{array}$ \\
\hline $\begin{array}{l}\text { Mamede et al. } \\
\text { (2018) }\end{array}$ & 15 & 2.1 & $1(7 \%)$ & $/$ & $0(0 \%)$ & 1 complex regional pain syndrome \\
\hline
\end{tabular}
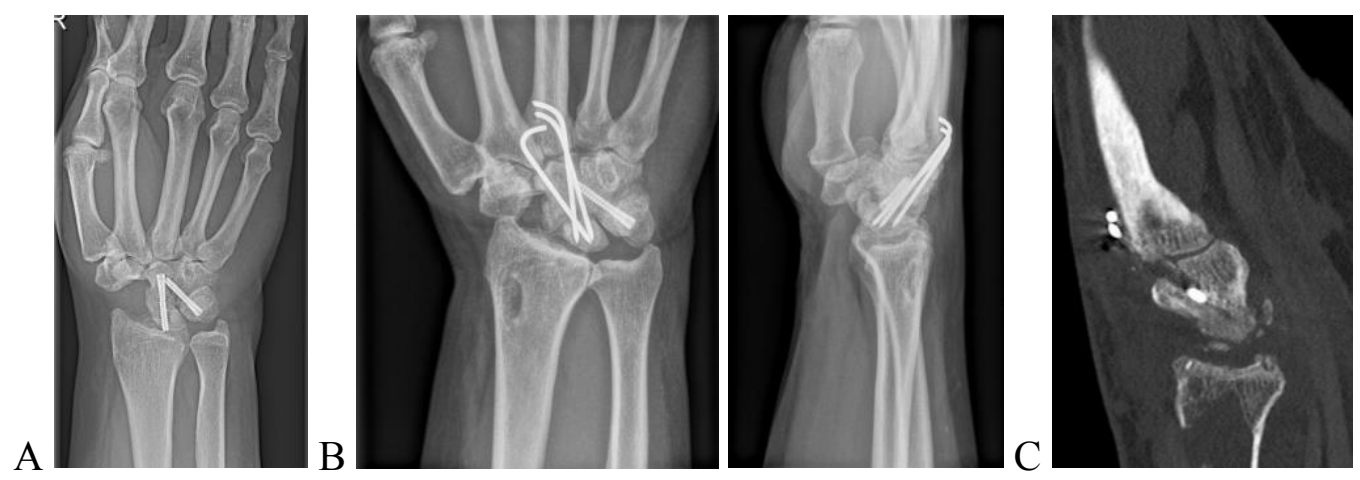

Figure 1. - Nonunion. A. Nonunion between lunate and capitate with screw fracture. B. Revision surgery was performed with removal of the broken screw, interposition of distal radial bone graft and K-wire fixation. C. CT-scan two months after surgery demonstrates successful bone healing.

Scaphoidectomy with 4-corner arthrodesis is a technically demanding procedure. Complication rate depends on the fixation method (13). Secondary operation rate in our study was found to be $19 \%$, far below the one observed by Williams et al. with different fixation techniques $(34,4 \%)$ (14).

The advantages of HCS are that they can be positioned perpendicular to the fusion site and that they provide compression, two factors that promote bone healing (7). In the literature, non-union rates after HCS fixation varies between $0-11 \%(6,8-10)$.
Treatment options for this complication have not been well described. We observed two patients that did not achieve primary healing of the midcarpal arthrodesis. The first patient had proximal migration, fracture and penetration of the capitolunate screw into the radiocarpal joint. This patient underwent revision surgery for screw removal and revision arthrodesis of the midcarpal joint with interposition of cancellous bone graft from the distal radius and fixation with 3 K-wires (Figure 1). Finally, successful bone healing with good clinical and 


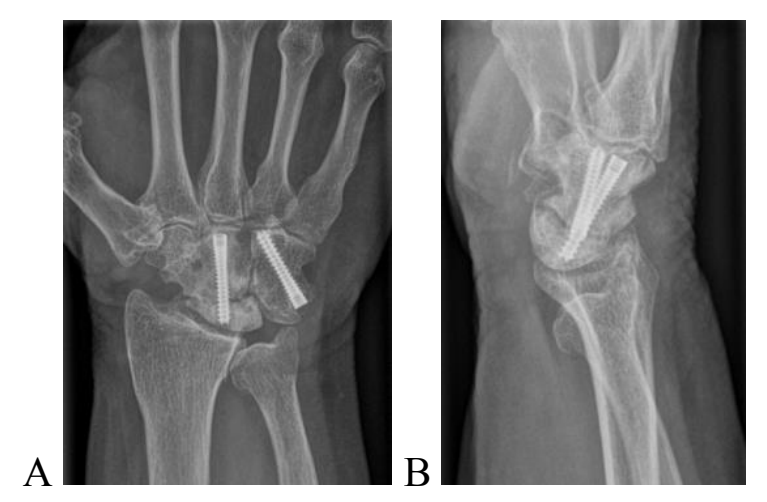

Figure 2. - Avascular necrosis of the lunate. Nonunion between lunate and capitate with radiographic signs of avascular necrosis of the lunate (bone sclerosis, interosseous cysts). A. AP view B. Lateral view.

radiographic outcome was obtained. The second patient had nonunion of the capitolunate articulation combined with avascular necrosis of the lunate (Figure 2). This was associated with a pain score of 3 in rest and 5 during activity. The patient did not find this debilitating enough to warrant secondary surgery.

Hardware problems are typically reported with fixation techniques that require dorsal hardware, with incidences of up to $31 \%$ (15). HCS can be buried inside the bone. This reduces the chance of hardware irritation. Hardware problems with HCS including loosening, screw fracture, intra-articular screw penetration and local irritation, range between 6-16\% (Table II). We observed one patient with secondary migration of the capitolunate screw into the radiocarpal joint at 4 months after surgery. Both screws were removed with uncomplicated further healing and good clinical results. In another patient, diffuse wrist pain continued after his surgery for avascular necrosis of the scaphoid. Postoperative radiographs showed adequate bone healing and no signs of implant related problems. Screw removal did not improve his complaints.

Excision of the pisiform bone was performed in three patients. In one patient, the pisiform was excised simultaneously with the 4-corner fusion because of preoperatively symptomatic pisotriquetral arthritis. In the other two patients, a pisiformectomy was performed respectively three

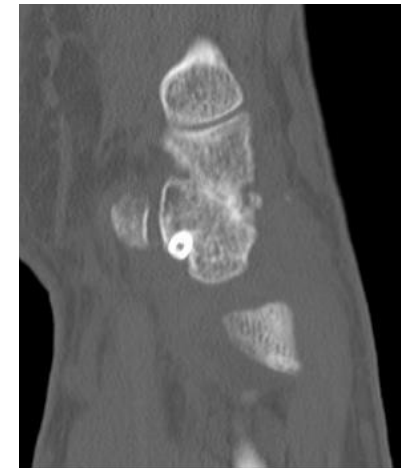

Figure 3. - Pisotriquetral screw penetration. Postoperative development of pain at the pisotriquetral joint. Sagittal computed tomography images show marginal intra-articular penetration of the screw.
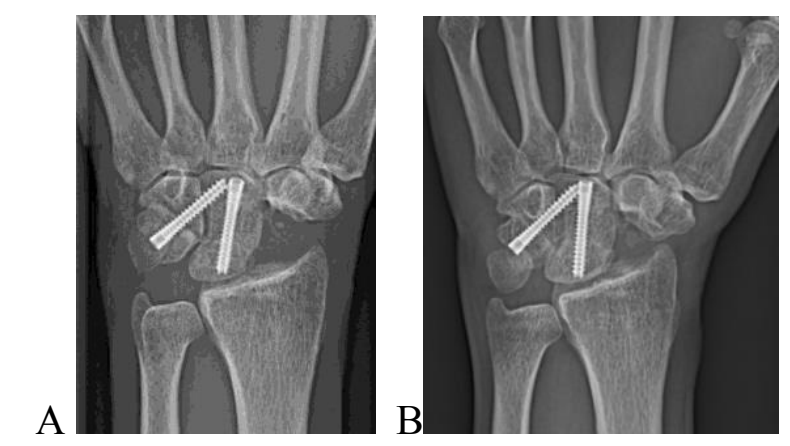

Figure 4. - Painful instability of the pisiform. Plain radiographs one month (A) and six months after surgery (B) show progressive proximal migration of the pisiform relative to the triquetrum.

and seven months after the initial surgery. In the first patient, pisotriquetral pain was caused by intraarticular penetration of the ulnar-sided screw (Figure 3 ). The second patient postoperatively developed a painful instability of the pisiform with clunking of the pisotriquetral joint during wrist motion (Figure 4). Both patients were symptom free after removal of the pisiform bone. The development of PT joint pathology after scaphoidectomy and 4-corner arthrodesis has been reported anecdotally $(3,16,17)$. First, the cartilage of the PT joint can be damaged by the initial trauma that caused the SNAC or SLAC wrist deformity. A scaphoid fracture or scapholunate ligament tear is typically caused by a fall on the outstretched hand. This typically requires impact on the palm of the hand, including the pisiform bone. 
Second, improper screw placement can damage the PT articular surfaces. Trail et al. reported 2 cases of pisiform excision that was indicated for incorrect screw placement after dorsal circular plate fixation (3). Third, PT joint contact pressure increases with wrist extension and DISI rotational deformity of the carpus $(16,18)$. Longstanding DISI deformity increases so the likelihood of PT osteoarthritis. Clinical examination of patients that are planned for scaphoidectomy and 4-corner fusion should therefore include PT shuck and compression tests. If any tenderness is revealed, concomitant pisiformectomy should be performed. Alternatively, the PT joint can be decompressed by removing the triquetrum and performing a lunate-capitatetriquetrum arthrodesis instead of a 4-corner fusion (19). PT osteoarthritis can also be confirmed with $\mathrm{x}$-ray examination. The joint can radiographically be visualized with a $30^{\circ}$ supinated view of the wrist in neutral position (16). This view should also be used during surgery to confirm correct screw placement.

One patient developed incapacitating wrist pain five years after surgery, possibly after a low impact trauma. Computed tomography showed densification and fracture of the lunate, suggesting avascular necrosis (Figure 5). She became completely pain free after total wrist fusion.

An incidence of secondary radiolunate arthritis of $66,6 \%$ has been reported with a follow-up of 15 years (20). With our minimum 2-year follow-up, we only observed this in 3\%. This needs further investigation as there are no series that use HCS screws with longer follow-up yet. Capitolunate fixation with HCS placed in a retrograde manner has the theoretical advantage of sparing the proximal lunate articular surface. The previously reported conversion rates to total wrist arthrodesis varies between 2.4 and $29 \%$, depending on the fixation technique that is used (8). HCS fixation scores remarkably lower with a conversion rate of only $0-4 \%$ (Table II).

One patient had temporary sensory dorsal ulnar nerve impairment. This nerve is specifically at risk when a HCS is inserted through a separate incision just distal to the ulnar styloid process. Sensation completely recovered one year postoperatively. Another patient experienced persistent hyper-

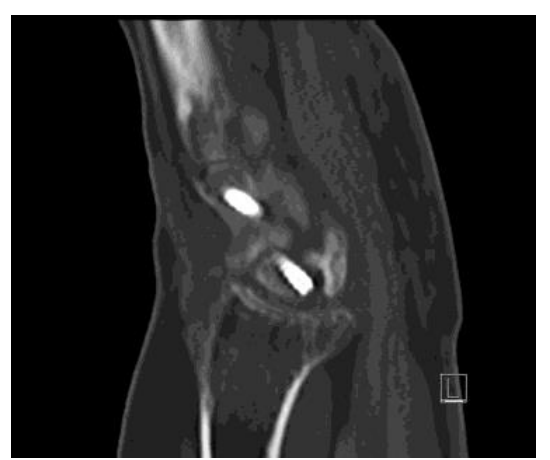

Figure 5. - Posttraumatic lunate avascular necrosis. Densification and fracture of the lunate five years after surgery, probably caused by avascular necrosis.

sensitivity around the scar on the dorsal side of the wrist. Ulna shortening osteotomy was performed in one patient, 4 years after her initial surgery, due to ulnocarpal impingement.

The present study evaluates a patient group of one technique of scaphoidectomy and 4-corner fusion performed by a single surgeon. Limitations are the retrospective design and the lack of preoperative measurements. The results of this study support the use of HCS for bone fixation and can help in decision making for complication management after 4-corner arthrodesis.

\section{CONCLUSION}

Scaphoidectomy and 4-corner arthrodesis with headless compression screws can provide good pain relief with functional residual wrist motion and strength. We observed postoperative complications in $28 \%$ of our patients. Most complications can successfully be treated with additional surgery.

\section{REFERENCES}

1. Watson HK, Ballet FL. The SLAC wrist : Scapholunate advanced collapse pattern of degenerative arthritis. J Hand Surg Am. 1984 ; 9(3) : 358-365.

2. Weiss KE, Rodner CM. Osteoarthritis of the Wrist. 2007.

3. Trail IA, Murali R, Stanley JK, Hayton MJ. The LongTerm Outcome of Four-Corner Fusion. J Wrist Surg. 2015 ; 4(212) : 128-133.

4. Krakauer JD, Bishop AT, Cooney WP. Surgical treatment of scapholunate advanced collapse. J Hand Surg Am. 1994 ; 19(5) : 751-759. 
5. Tomaino MM, Miller RJ, Cole I, Burton RI. Scapholunate advanced collapse wrist: Proximal row carpectomy or limited wrist arthrodesis with scaphoid excision? J Hand Surg Am. 1994 ; 19(1) : 134-142.

6. Iordache SS, Nam D, Peylan J, Exelrod T. Four-corner arthrodesis using two headless compression screws. Acta Orthop Belg. 2016 ; 82 : 332-338.

7. Greenberg A, Shreve M, Bazylewicz D, Goldstein R, Sapienza A. Early Motion Following 4-Corner Arthrodesis Using Cannulated Compression Screws : A Biomechanical Study. J Hand Surg Am. 2013 ; 38(11) : 2180-2187.

8. Ozyurekoglu T, Turker T. Results of a Method of 4-Corner Arthrodesis Using. YJHSU. 2011 ; 37(3) : 486-492

9. Draeger RW, Jr DKB, Bs AS, Patterson JMM. Bicolumnar Intercarpal Arthrodesis: Minimum 2-Year Follow-Up. J Hand Surg Am. 2014 ; 39(5) : 888-894.

10. Mamede J, Adeodato SC, Leal RA. Four-Corner Arthrodesis: Description of Surgical Technique Using Headless Retrograde Crossed Screws. 2018.

11. Richards AA, Afifi AM, Moneim MS. Four-Corner Fusion and Scaphoid Excision Using Headless Compression Screws for SLAC and SNAC Wrist Deformities. 2011 ; 15(2) : 99-103.

12. Tang JB, Giddens G. Why and how to report surgeons' levels of expertise. J Hand Surg Am. 2016 ; 41E(4) : 365366.

13. Henry M. Internal headless compression screw method for 4-corner fusion. $2009 ; 1(1): 45-49$.
14. Williams J, Weiner H, Tyser A. Long-Term Outcome and Secondary Operations after Proximal Row Carpectomy or Four-Corner Arthrodesis. J Wrist Surg. 2018 ; 07(01) : 051056.

15. Pauchard N, Lecoanet-Strugarek C, Segret J, De Gasperi M, Dap F, Dautel G. Dorsal locking plates versus staples in four-corner fusion: A comparative clinical and radiological study. Orthop Traumatol Surg Res. 2014 ; 100(6) : 593-597.

16. Gaston RG, Lourie GM, Iii WEF, Swick M. Pisotriquetral Dysfunction Following Limited and Total Wrist Arthrodesis. 2005 : 1348-1355.

17. Gaston RG, Greenberg JA, Baltera RM, Mih A, Hastings H. Clinical Outcomes of Scaphoid and Triquetral Excision With Capitolunate Arthrodesis Versus Scaphoid Excision and Four-Corner Arthrodesis. J Hand Surg Am. 2009 ; 34(8) : 1407-1412.

18. Beckers A, Koebke J. Mechanical strain at the pisotriquetral joint. Clin Anat. 1998 ; 11(5) : 320-326.

19. Delattre O, Goulon G, Vogels J, Wavreille G, Lasnier A. Three-corner arthrodesis with scaphoid and triquetrum excision for wrist arthritis. J Hand Surg Am. 2015 ; 40(11) : 2176-2182.

20. Neubrech F, Mühldorfer-Fodor M, Pillukat T, Schoonhoven J, Prommersberger K. Long-Term Results after Midcarpal Arthrodesis. J Wrist Surg. 2012 ; 01(02) : 123-128. 